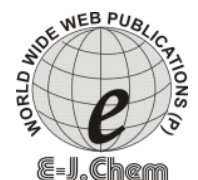

http://www.ejchem.net

ISSN: 0973-4945; CODEN ECJHAO

E-Journal of Chemistry

2012, 9(2), 642-649

\title{
Kinetics and Mechanism of Oxidation of Diethyl Ether by Chloramine-T in Acidic Medium
}

\author{
Y. I. HASSAN ${ }^{*}$ and N. H. M. SAEED
}

\author{
Department of Chemistry \\ College of Education, University of Mosul, Mosul, Iraq \\ youhassan51@yahoo.com
}

Received 7 July 2011; Accepted 20 September 2011

\begin{abstract}
The kinetics of oxidation of diethyl ether (DE) with sodium N-chloro-p-toluenesulphonamide (CAT) in hydrochloric acid solution has been studied at $\left(313^{\circ} \mathrm{K}\right)$. The reaction rate show a first order dependence on [CAT] and fractional order dependence on each $[\mathrm{DE}]$ and $\left[\mathrm{H}^{+}\right]$. The variation of ionic strength of the medium has no significant effect on the reaction rate, addition of p-toluenesulphonamide (p-TSA) affects the reaction rate marginally the rate increased with decreasing dielectric constant of the medium , the stochiometry of the reaction was found to be 1:2 and oxidation products were identified, A Michaelis - Menten type mechanism has been suggested to explain the results. The equilibrium and the decomposition constants of CAT - diethyl ether complex have been evaluated. Thermodynamic parameters were computed by studying reaction at temperatures range ( $308-$ $323^{\circ} \mathrm{K}$ ) for the rate limiting step and for the observed first order constants by the linear Arrhenius plot. The mechanism proposed and the derived rate law are consistent with observed kinetics.
\end{abstract}

Keywords: Oxidation kinetic, Diethyl ether, Chloramine-T, Acidic medium.

\section{Introduction}

The versatile nature of aromatic sulphonyl haloaminesis due to their ability to act as sources of halonium cations, hypohalite species and nitrogen anion which act as both bases and nucleophilies .Sodium-N-chloro-P-toluenesulphonamide $\left(\mathrm{p}-\mathrm{CH}_{3}-\mathrm{C}_{6} \mathrm{H}_{4} \mathrm{SO}_{2} \mathrm{NClNa} .3 \mathrm{H}_{2} \mathrm{O}\right)$, well known as chloramine-T (CAT, R'NCINa), is a very important member of this class of compounds and has received a considerable attention as an oxidizing agent for a wide range of functional groups in both acidic and alkaline media. Generally, Chloramine-T undergoes a two-electrons change in its reactions, the products being p-toluenesulphonamide (p-TSA) and sodium chloride. The redox potential of CAT/ $\mathrm{RNH}_{2}$ is $\mathrm{pH}$ dependent and decrease with an increase in $\mathrm{pH}$ dependent and decrease with an increase in the $\mathrm{pH}$ of the medium ,having the values of 1.14 at $\mathrm{pH} 0.65$ and 0.5 at $\mathrm{pH} 12^{1,2}$. Depending on the $\mathrm{pH}$ of the medium CAT 
furnishes different types of reactive species in solution, such as N-chloro-ptoluenesulphonamide (R'NHCl,monochloramine- $\mathrm{T}$, where $\mathrm{R}=\mathrm{P}-\mathrm{CH}_{3} \mathrm{C}_{6} \mathrm{H}_{4} \mathrm{SO}_{2}$ ), dichloramine- $\mathrm{T}\left(\mathrm{R}^{\prime} \mathrm{NCl}_{2}\right), \mathrm{HOCl}$ and possibly $\mathrm{H}_{2} \mathrm{O}^{+} \mathrm{CL}$ and $\mathrm{RNH}_{2}^{+} \mathrm{Cl}$ in acid solution and $\mathrm{R}^{\prime} \mathrm{NCl}^{-}$and $\mathrm{OCl}^{-}$in alkaline medium .Free chlorine has also been detected in medium in the presence of chloride ion ${ }^{3}$. Although this reagent has been widely ulitized for the quantitative determination of a large number of inorganic and organic compoundsin solution ${ }^{4,5}$, only a few kinetic studies have been carried out .Mention may be made about the oxidation of

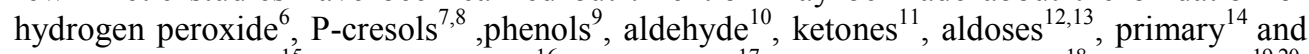
secondary alcohols ${ }^{15}, \alpha$-hydroxy acid $^{16}$,formic acid ${ }^{17}$, furan-2-carboxic acid ${ }^{18}$, amino acid ${ }^{19,20}$, aniline $^{21}$, toluene ${ }^{22}$, acetanilide ${ }^{23}$ catecholamines $^{24}$, sulphoxides ${ }^{25,26}$, cyanide ${ }^{27}$ and thiocynat ${ }^{28}$ by CAT.

Diethyl ether is widely used as a solvent, a reaction medium and to avery low extent as reactant. It can be oxidize to acetic acid with sodium bromate ${ }^{29}$. The present work is an attempt to find out the nature of reacting species and to explore the mechanistic pathway involved in the oxidation of diethyl ether, since, such study has not previously been (fully) explored.

\section{Experimental}

Diethyl ethers (fluka) of spectrophotoscopic grade used as recived. Chloramine-T was prepared as reported in the literature ${ }^{(30)}$ and purified by the method of Morris et $a l^{31}$. An aqueous solution of CAT was standaraized by iodometric method and preservedin brown bottles to prevent its photo chemical deterioration. All other reagents were of Analar grade and used as supplied. The ionic strength of the system was kept at a high value by using sodium perchlorate.

\section{Kinetic measurements}

The reaction was carried out in glass stoppered pyress boiling tubes, under pseudo -first order condition by keeping diethyl ether concentration large in comparison with [CAT].Appropriate amounts of diethyl ether, hydrochloric acid sodium perchlorate solutions, and water (to keep the total volume constant for all runs)were taken in the tubeand thermostated at $40{ }^{\circ} \mathrm{C}$ for the thermal equilibrium. A desired amount of thermostated CAT at the same temperature was rapidly added to the mixture in the bolling tube. The progress of the reaction was followed by with drwawing a measured samples at various time intervals to the quenched solution (5\% potassium iodide, $2 \mathrm{M}$ sulphuric acid) and water in a volumetricacid. The liberated iodine was estimated spectrophotometrically at $353 \mathrm{~nm}$. The course of reaction was studied for at least two half -lives. The pseudo -first order rate constant calculated from the slope of the plots of [CAT] vs. time, were reproducible within $\pm 3 \%$.

\section{Stoichiometry}

Varying ratios of CAT to diethyl ether in the presence of $0.2 \mathrm{M} \mathrm{HCl}$, ethanol and water were equilibrated at $313 \mathrm{~K}^{\circ}$ for $24 \mathrm{~h}$. Estimation of residual oxidant showed that 2 mole of CAT is consumed per mole of dietyl ether. The stoichiometry obtained can be represented as:

$$
\mathrm{CH}_{3} \mathrm{CH}_{2} \mathrm{OCH}_{2} \mathrm{CH}_{3}+2 \mathrm{R}^{\prime} \mathrm{NClNa}+\mathrm{H}_{2} \mathrm{O} \stackrel{\mathrm{H}^{+} \rightarrow}{\longrightarrow} \begin{aligned}
& \mathrm{CH}_{3} \mathrm{COOH}+\mathrm{CH}_{3} \mathrm{CH}_{2} \mathrm{OH} \\
& +2 \mathrm{R}^{\prime} \mathrm{NH}_{2}+2 \mathrm{Na}^{+}+2 \mathrm{Cl}^{-}
\end{aligned}
$$

p-Toluenesulphonamide among the reaction products was detected by paper chromatography. Benzyl alchohol satutrated with water was used as the solvent with $0.5 \%$ vaniline in $1 \% \mathrm{HCl}$ solution in ethanol as spray reagent $\left(\mathrm{R}_{\mathrm{F}}=0.905\right)^{32,33}$. The acetic 
acid produced was identified by conversion to hydro - oximic acid derivative ${ }^{34}$ which give violate color with ferric ion .or formation of deep-red coloration on reaction with practically neutral or basic solution of ferric chloride ${ }^{35}$.

\section{Results and Discussion}

The kinetics of oxidation of diethyl ether (DE), by chloramine-T was investigated at several initial concentration of reactants in acid medium.

\section{Effect of varying reactant concentration}

At constant acid concentration with the substrate in excess ,plots of log [CAT] vs. time were linear $(r>0.9954)$, indicating a first -order rate dependence of rate on [CAT] . The pseudo first-order rate constant $\left(\mathrm{k}^{\prime}\right)$ are given in Table 1 . The values of $\mathrm{k}^{\prime}$ increase with substrate concentration. Plot of $\log \mathrm{k}^{\prime} v s$. $\log [\mathrm{DE}]$ gives a straight line $(\mathrm{r}=0.9931)$ with slope of (0.52) indicating a fractional -order dependence on the substrate concentration .

\section{Effect of varying $\left[\mathrm{H}^{+}\right]$}

The reaction rate will increase with increase in $\left[\mathrm{H}^{+}\right]$, Table 1 . A plot of $\log \mathrm{k}^{\prime} v s . \log [\mathrm{H}]$ was linear $(\mathrm{r}=0.9960 \%)$ with slope of $(0.53)$, thus indicating a fractional -order dependence on the $\left[\mathrm{H}^{+}\right]$

\section{Effect of varying ionic strength on p-Toluenesulphonamide}

Variation of ionic strength of the medium $(0.125-0.625 \mathrm{M})$ by adding concentrated solution of sodium perchlorate, has no significant effect on the reaction rate. Also addition of $p$ toluenesulphonamide ( $p$-TSA) affected the reaction rate marginally Table 2.

\section{Effect of changing the solvent composition}

The first-order rate constant $\mathrm{k}^{\prime}$ was affected by variation of methanol in the methanol-water content or the reaction mixture with [methanol] $=20,30,40,50$, and $60 \%, 10^{4} \mathrm{k}^{\prime} \mathrm{sec}^{-1}$ values were $3.071,5.374,8.061,9.212$ and 13.434 respectivly. A plot of $\log \mathrm{k}^{\prime} v s .1 / \mathrm{D}$ (dielectric constant values were taken from literature $\left.{ }^{35}\right)$ gives a straight line $(\mathrm{r}=0.9884)$ with a positive slope.

\section{Effect of temperature}

Kinetics were studied at different temperatures $\left(308-323 \mathrm{~K}^{\circ}\right)$ under varying substrate concentrations $(0.48-2.41 \mathrm{M})$. Plots of $\log \mathrm{k}^{\prime}$ versus $\log [\mathrm{DE}]$ were linear $(\mathrm{r}>0.9570)$ with slopes $(0.563,0.528,0.503,0.503$ and 0.511$)$ at $308,313,318,323$, and $328 \mathrm{~K}^{\mathrm{o}}$ for each of [DE],respectively, indicating fractional -order dependence on substrate . The rate constant of the slow step $\left(\mathrm{k}_{3}\right)$ was obtained from the intercept of the linear plot $1 / \mathrm{k}^{\prime}$ versus $1 /[\mathrm{DE}]$. $(\mathrm{r}=0.9852)$. From the linear Arrhenius plot of $\log \mathrm{k}^{\prime}$ versus $1 / \mathrm{T}(\mathrm{r}=0.9980)$ the activation energy and other thermodynamic parameters for composite and reaction for the rate limiting step were evaluated. These values are given in Table 3 . 
Table 1. Effect of varying of chloramine-T, diethyl ether, and hydrogen ion concentration on the reaction rate.

\begin{tabular}{ccccc}
\hline $10^{3}[\mathrm{CAT}] \mathrm{M}$ & {$[\mathrm{DE}] \mathrm{M}$} & $10\left[\mathrm{H}^{+}\right] \mathrm{M}$ & $10^{4} \mathrm{k} \mathrm{Sec}^{-1}$ & $10^{4} \mathrm{k}^{\mathrm{a}}$ \\
\hline 1.50 & 0.96 & 3.0 & 3.071 & \\
1.75 & 0.96 & 3.0 & 3.070 & \\
2.00 & 0.96 & 3.0 & 2.986 & \\
2.25 & 0.96 & 3.0 & 2.986 & \\
2.50 & 0.96 & 3.0 & 3.081 & \\
1.50 & 0.48 & 3.0 & 2.303 & 3.393 \\
1.50 & 0.96 & 3.0 & 3.071 & 3.138 \\
1.50 & 1.45 & 3.0 & 3.455 & 2.839 \\
1.50 & 1.93 & 3.0 & 3.838 & 3.154 \\
1.50 & 2.41 & 3.0 & 4.606 & 2.895 \\
1.50 & 0.96 & 2 & 2.508 & 5.848 \\
1.50 & 0.96 & 2.5 & 2.850 & 5.909 \\
1.50 & 0.96 & 3 & 3.071 & 5.785 \\
1.50 & 0.96 & 3.5 & 3.372 & 5.857 \\
1.50 & 0.96 & 4 & 3.629 & 5.876 \\
\hline
\end{tabular}

$T=313 K^{0}$ in (1:5) ethanol: water $(v / v), \mu=0.5$ M. Note. a $k=k^{\prime} /\left[D E \text { or } H^{+}\right]^{n}$, where $n$ is slope of the plot $\log k^{\prime}$ vs $\log \left[D E\right.$ or $\left.H^{+}\right] k$ has the units of $L^{h} \mathrm{~mol}^{-n} \sec ^{-1}$.

Table 2. Effect of varying ionic strength and [P-TSA] on the reaction rate.

\begin{tabular}{cccc}
\hline$\left[\mathrm{NaClO}_{4}\right] \mathrm{M}$ & $10^{4} \mathrm{k} \mathrm{Sec}^{-1}$ & $10^{3}[\mathrm{P}-\mathrm{TSA}] \mathrm{M}$ & $10^{4} \mathrm{k} \mathrm{Sec}^{-1}$ \\
\hline 0.125 & 3.071 & 1.25 & 3.000 \\
0.250 & 3.062 & 2.50 & 2.851 \\
0.375 & 3.079 & 3.75 & 2.590 \\
0.500 & 3.075 & 5.00 & 2.412 \\
0.625 & 3.071 & 6.25 & 2.374 \\
$T=313 \mathrm{~K},[D E]=0.96 \mathrm{M},[C A T]=0.001$ M in (1:5) ethanol : water $(v / v)$ and $\mu=0.25 \mathrm{M}_{\text {while varying }}$ \\
[P-TSA].
\end{tabular}

Table 3. Effect of temperature on the reaction rate and activation parameters.

\begin{tabular}{|c|c|c|c|}
\hline Temperature $\mathrm{K}^{0}$ & $10^{4} \mathrm{k} \mathrm{Sec}^{-1}$ & $10^{4} \mathrm{k}_{3} \mathrm{Sec}^{-1}$ & Activation Parameters \\
\hline 308 & 2.00 & $(6.83)$ & Ea , KJ mol-1 84.955 (77.22) \\
\hline 313 & 3.07 & $(7.89)$ & $\Delta \mathrm{H} \neq, \mathrm{KJ}$ mol-1 $82.309 \pm 0.084(74.575 \pm 0.083)$ \\
\hline 318 & 3.84 & $(15.15)$ & $\Delta \mathrm{S} \neq, \mathrm{JK}-1 \mathrm{~mol}-1-47.766 \pm 1.844(-65.156 \pm 178)$ \\
\hline 323 & 4.61 & $(19.60)$ & $\Delta \mathrm{G} \neq, \mathrm{K} J \mathrm{~mol}-197.509 \pm 0.884(95.305 \pm 1.07)$ \\
\hline 328 & 5.20 & $(43.48)$ & $10^{-10} \mathrm{~A}$, sec- $1 \quad 5.822 \pm 1.275(0.7205 \pm 0.1301)$ \\
\hline
\end{tabular}

$\mu=0.25 \mathrm{M}$, (1:5) ethanol : water $(v / v),[C A T]=0.001 \mathrm{M},[D E]=0.96 \mathrm{M},\left[\mathrm{H}^{+}\right]=0.3 \mathrm{M}$ and Note. values in parenthesis are the decomposition constant and activation parameters limiting step.

Chloramine-T behaves like a strong electrolyte in aqueous solution and dissociates according to equation (2). The anion picks up a proton in acid solutions to give the free acid has not been isolated there is an experimental evidence for its formation in acid solution .It undergoes disproportionation giving rise to $p$-toluenesulphonamide and dichloramine-T ,equation(4). Dichloramine-T and the free acid hydrolyse to give hypochlorus acid , $\mathrm{HOCl}$ ,[equation (5) and (6)]. Hypochlorous acid produce can be ionize according to equation (7). 
hypochlorus acidinium ion $\left(\mathrm{H}_{2} \mathrm{O}^{+} \mathrm{Cl}\right)$ and protonated monochloramine- $\mathrm{T}\left(\mathrm{R}^{\prime} \mathrm{N}^{+} \mathrm{H}_{2} \mathrm{Cl}\right)$ have also been detected in acid medium through equation (8) and equation (9), respectively.

$$
\begin{gathered}
\mathrm{R}^{\prime} \mathrm{NCINa} \rightleftarrows \mathrm{R}^{\prime} \mathrm{NCI}+\mathrm{Na}^{+} \\
\mathrm{R}^{\prime} \mathrm{NCI}+\mathrm{H}^{+} \rightleftarrows \mathrm{R}^{\prime} \mathrm{NHCI} \\
2 \mathrm{R}^{\prime} \mathrm{NHCI} \rightleftarrows \mathrm{R}^{\prime} \mathrm{NCI}_{2}+\mathrm{RNH}_{2} \\
\mathrm{R}^{\prime} \mathrm{NCI}_{2}+\mathrm{H}_{2} \mathrm{O} \rightleftarrows \mathrm{R}^{\prime} \mathrm{NHCI}_{2}+\mathrm{HOCI} \\
\mathrm{R}^{\prime} \mathrm{NHCI}_{2}+\mathrm{H}_{2} \mathrm{O} \rightleftarrows \mathrm{RNH}_{2}+\mathrm{HOCI} \\
\mathrm{HOCI} \rightleftarrows \mathrm{H}+\mathrm{OCI}^{-} \\
\mathrm{HOCI}+\mathrm{H}^{+}+\mathrm{CI}-\rightleftarrows \mathrm{H}_{2} \mathrm{O}+\mathrm{CI}_{2} \\
\mathrm{R}^{\prime} \mathrm{NHCI}+\mathrm{H}^{+} \rightleftarrows \mathrm{R}^{\prime} \mathrm{NH}_{2} \mathrm{CI} \\
\text { rate }=\mathrm{d}[\mathrm{CAT}] / \mathrm{dt}=\mathrm{k} 3[\mathrm{X}]
\end{gathered}
$$

Therefore the possible reactive species in acidified chloramine- $\mathrm{T}$ solutions are $\mathrm{R} \mathrm{NHCl}$, $\mathrm{R}^{\prime} \mathrm{NCl}_{2}, \mathrm{HOCl}, \mathrm{Cl}_{2}$, and probably $\left(\mathrm{RNH}^{+} 2 \mathrm{Cl}\right.$ and $\mathrm{H}_{2} \mathrm{O}^{+} \mathrm{CL}$ ). If $\mathrm{RNCl}_{2}$ were to be the reactive species then the rate predicats a second -order dependence of rate on CAT but experimentally clear first -order plots were obtained for disappearance of CAT. Equation (6) indicates that the hydrolysis is slight and if $\mathrm{HOCl}$ is involved a first -order retardation of rate by the added P-toluenesulphonamide is expected. However ,no such effect was observed .first -approximation calculations by Bishop and Jennings ${ }^{(36)}$ on $0.05 \mathrm{M}$ solution of CAT have shown that the concentration of $\mathrm{RNHCl}$ and $\mathrm{HOCl}$ are $10^{-2}$ and $10^{-7} \mathrm{M}$, respectively ; at $\mathrm{PH}<3$. Under the present experimental conditions $\left(0.2-0.4 \mathrm{M} \mathrm{H}^{+}\right)$, it is quite likely that $\mathrm{R} \mathrm{NHCl}$ is the oxidizing species variation of ionic strength of medium or addition of the reaction product. $P$-toluenesulphonamide, have virtually no effect on the rate. Bearing these facts in mind, the following scheme 1 has been proposed;

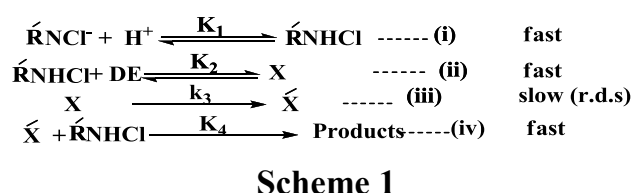

In scheme $1, \mathrm{DE}$ represent the substrare, $\mathrm{X}$ and $\mathrm{X}$ represents the complex intermediate species whose structures are shown in scheme 2, where a details plausible mechanism of oxidation of DE with CAT in $\mathrm{HCl}$ medium is illustrated.

From the slow step of scheme 1,

$$
\text { rate }=\frac{\mathrm{d}[\mathrm{CAT}]=\mathrm{k}_{3}[\mathrm{X}]}{\mathrm{dt}}
$$

If $[\mathrm{CAT}]_{\mathrm{t}}$ is the total effective concentration of CAT, then

$$
[\mathrm{CAT}]_{\mathrm{t}}=\left[\mathrm{R}^{\prime} \mathrm{NCl}^{-}\right]+\left[\mathrm{R}^{\prime} \mathrm{NHCl}\right]+[\mathrm{X}]
$$

By substituting for [ $\left.\mathrm{R}^{\prime} \mathrm{NCl}\right]$ and [ $\left.\mathrm{R}^{\prime} \mathrm{NHCl}\right]$ from step (i) and (ii) in scheme 1, respectively, in to equation (11) and solving for $[\mathrm{X}]$, one obtains; 


$$
\begin{gathered}
{[\mathrm{CAT}]_{\mathrm{t}}=\frac{[\mathrm{X}]}{\mathrm{K}_{1} \mathrm{~K}_{2}[\mathrm{DE}][\mathrm{H}+]}+\frac{[\mathrm{X}]}{\mathrm{K}_{2}[\mathrm{DE}]}+[\mathrm{X}]} \\
{[\mathrm{X}]=\frac{\mathrm{K}_{1} \mathrm{~K}_{2}[\mathrm{DE}]\left[\mathrm{H}^{+}\right][\mathrm{CAT}] \mathrm{t}}{1+\mathrm{K}_{1}\left[\mathrm{H}^{+}\right]+\mathrm{K}_{1} \mathrm{~K}_{2}[\mathrm{DE}]\left[\mathrm{H}^{+}\right]}}
\end{gathered}
$$

Substituting equation (13) in equation (10), the following, rate law can be obtained;

$$
\text { rate }=\frac{\mathrm{d}[\mathrm{CAT}] \mathrm{t}}{\mathrm{dt}}=\frac{\mathrm{K}_{1} \mathrm{~K}_{2} \mathrm{k}_{3}[\mathrm{DE}]\left[\mathrm{H}^{+}\right][\mathrm{CAT}] \mathrm{t}}{1+\mathrm{K}_{1}\left[\mathrm{H}^{+}\right]+\mathrm{K}_{1} \mathrm{~K}_{2}[\mathrm{DE}]\left[\mathrm{H}^{+}\right]}
$$

Rate law (14) is in good agreement with the experimental results, where in a first -order dependence of rate on $[\mathrm{CAT}]$, a fractional order dependence on both $[\mathrm{DE}]$ and $\left[\mathrm{H}^{+}\right]$have been observed . Since rate $=\mathrm{k}_{1}[\mathrm{CAT}]_{\mathrm{t}}$, equation (14) can be transformed in to equations (1517)

$$
\begin{gathered}
\mathrm{k}^{\prime} \mathrm{k}^{\prime}=\frac{\mathrm{K}_{1} \mathrm{~K}_{2} \mathrm{k}_{3}[\mathrm{DE}]\left[\mathrm{H}^{+}\right]}{1+\mathrm{K}_{1}\left[\mathrm{H}^{+}\right]+\mathrm{K}_{1} \mathrm{~K}_{2}[\mathrm{DE}]\left[\mathrm{H}^{+}\right]} \\
\frac{1}{\mathrm{k}}=\frac{1}{\mathrm{~K}_{1} \mathrm{~K}_{2} \mathrm{k}_{3}[\mathrm{DE}]\left[\mathrm{H}^{+}\right]}+\frac{1}{\mathrm{~K}_{2} \mathrm{k}_{3}[\mathrm{DE}]}+\frac{1}{\mathrm{k}_{3}} \\
\frac{1}{\mathrm{k}}=\frac{1}{\mathrm{~K}_{2} \mathrm{k}_{3}[\mathrm{DE}]}\left\{\frac{1}{\mathrm{~K}_{1}\left[\mathrm{H}^{+}\right]}+1\right\}+\frac{1}{\mathrm{k}_{3}}
\end{gathered}
$$

Based on equations (16) and (17), plots of $1 / \mathrm{k}^{\prime}$ versus $1 /[\mathrm{DE}]$ and $1 / \mathrm{k}^{\prime}$ versus $1 /\left[\mathrm{H}^{+}\right]$ were linear $(r>0.9910)$ (Figure 1) from the intercepts and slopes of these plots values of formation constant $\mathrm{k}_{3}$ calculated and found to be $\mathrm{K}_{1}=1.34 \mathrm{~mol} . \mathrm{dm}^{-3}, \mathrm{~K}_{2}=2.06 \mathrm{dm} \cdot \mathrm{mol}^{-1}$ and $\mathrm{k}_{3}=7.886^{*} 10^{-3} \mathrm{sec}^{-1}$ at $313 \mathrm{~K}^{0}$ respectively. Since the rate was fractional -order in $[\mathrm{DE}]_{0}$, Michaelis - Menten $^{37}$ kinetics were adopted to study the effect of $[D E]_{0}$ on the rate at different temperatures $\left(308-343^{\circ} \mathrm{k}\right)$ by plotting $1 / \mathrm{k}^{\prime}$ versus $1 /[\mathrm{DE}]_{0}$. Using the calculated $\mathrm{k}_{3}$ and the observed rate constants $\mathrm{k}$ ' values, activation parameters were evaluated from linear Arrhenuis plot of $1 / \mathrm{k}^{\prime}$ versus $1 / \mathrm{T}$. the values are recorded in Table 3.
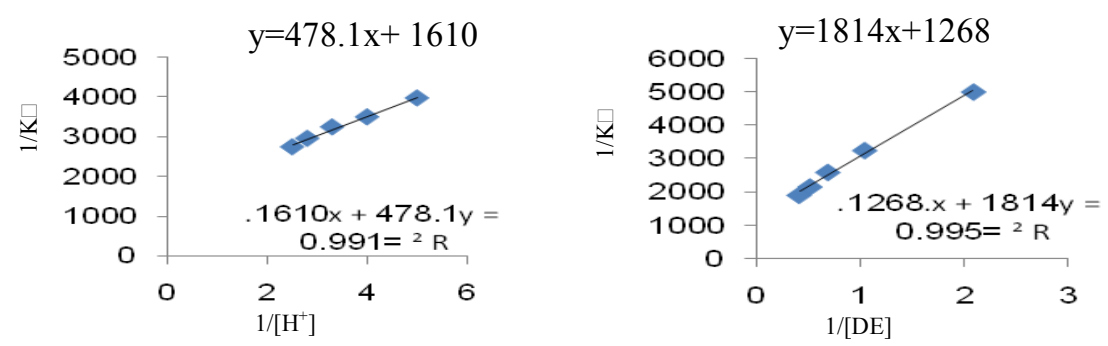

Figure 1. plot of $1 / \mathrm{k}^{\mathrm{o}}$ versus $1 /\left[\mathrm{H}^{+}\right]$and $1 /[\mathrm{DE}] ;[\mathrm{CAT}]=0.001 \mathrm{M} ; \mu=0.25 \mathrm{M}$;

Temperature $=313 \mathrm{~K}^{\circ}$. 


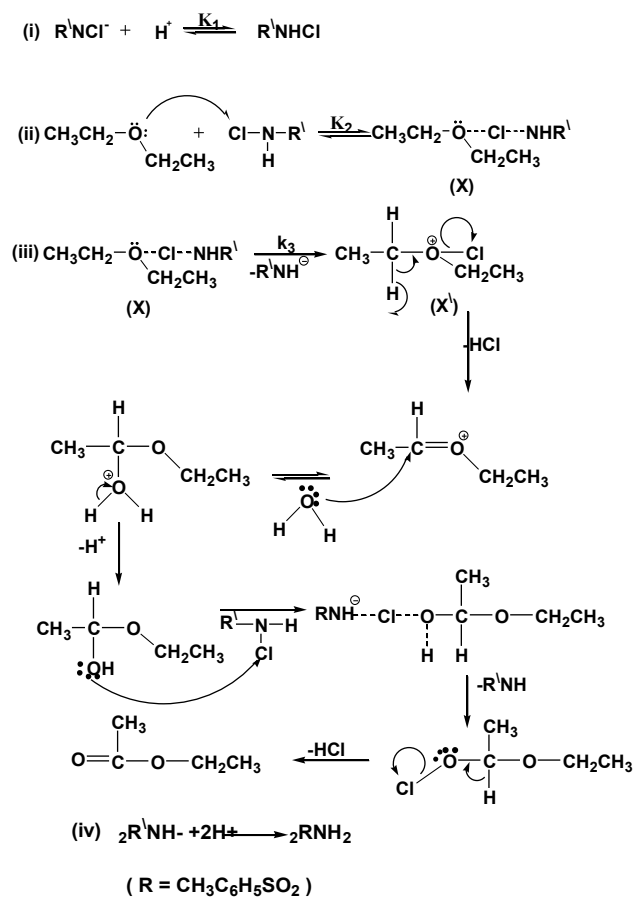

Scheme 2

The propose mechanism and the derived rate law are supported by the experimental data and findings ; there is a good agreement between them indicating the consistency and the correctness of the proposed Schemes and the derived rate law ,except that for $\left(\mathrm{K}_{1}\right)$ value ,which may be due to variation of experimental condition. The reaction rate is un altered by the variation of ionic strength of the medium .Addition of the reaction product P-TSA affects the reaction rate marginally showing that it is not involved in a pre -equilibrium. A change in the solvent composition by varying the methanol content in methanol -water affects the reaction rate which has been describe in detail by frost and pearson ${ }^{38}$, laidler ${ }^{39}$ and $\mathrm{Amis}^{40}$. For the limiting case of zero angle of approach between two dipoles or an iondipole system, Amis ${ }^{(40)}$ has shown that a plot of $\log \mathrm{k}^{\prime}$ versus 1/D gives a straight line, with a negative ion and a dipole or between two dipoles, whiles a positive results for a positive ion -dipole interaction. The latter concept agrees with the present investigation where a positive ion may be involved in the rate determining step (which extended to the transition state) of the proposed mechanism. The propose mechanism is also supported by the moderate $\Delta \mathrm{H}^{\neq}$and $\Delta \mathrm{G}^{\neq}$values and by the high negative value of $\Delta \mathrm{S}^{\ddagger}$ which indicate that the transition state is more ordered than the reactants.

\section{Conclusion}

Oxidation of diethyl ether with chloramine- $\mathrm{T}$ in $\mathrm{HCl}$ medium has been studied the stoichiometry of oxidation diethyl ether with CAT in acid medium is found to be 1:2. The oxidation product identified was ethyl acetate .The active oxidizing species involved in acid medium is $\mathrm{CH}_{3} \mathrm{C}_{6} \mathrm{H}_{4} \mathrm{SO}_{2} \mathrm{NHCl}$.Activation parameters calculated from Arrhenius plot the observed results supported the proposed mechanism and derived rate law. 


\section{References}

1. Murthy.A R V and Rao.V R S, Proc Indian Acad Sci., 1952, 69, 35.

2. Cambell M M and Johnson.G, Chem Rev., 1978. 78, 65.

3. Rao.V.R.S, Venkappayya.D and Aravamudan.G, Talanta, 1970, 17, 770.

4. KolthoffI.M and Belcher R, "Volumetric Analysis" Vol.3, Interscience, New York, 1975, P639.

5. Jennings V J, CRC Crit Rev Anal Chem., 1964, 407.

6. Coull J, Hope H B and Gouguell.B, J Am Chem Soc., 1935, 57, 1489.

7. Pryde L R and Soper F G, J Chem Soc., 1931, 1510.

8. Higuchi T and Hussain A, J Chem Soc., 1967, B, 549.

9. Balasubramania.V and Thiagarajain.V, Int J Chem Kinet., 1975, 7, 605.

10. Agrawal M C and Mushran S P, Naturfrosch., 1972, B27, 401.

11. Bose A K, Sanehi R and Mushran S P, J Indian Chem Soc., 1973, 50,197 .

12. Agrawal M C and Mushran S P, J Chem Soc Perken Trans II, 1973, 762.

13. Rangappa K S, Manjunathaswamy H, Ragharendra M P and Gowda D C, Carbohydrate Reseach., 1998,307,253.

14. Mahadevappa D S and Naidu H M K, Aust J Chem., 1974, 27, 1203; 1975, 28, 899.

15. Natarajam M M and Thaiagarajan V, J Chem Soc Perken Trans., 1975, II, 1590.

16. Mushran S P, Agrawal M C and Prased B, J Chem Soc., 1971, 1712 .

17. Hassan Y I, Aziz L A and AL-Joraycee A A, J Edec. and Sci., 1989, 9, 73.

18. Hassan Y I and AL-Hatim A A, Mutah J Res Stud., 1995, 5, 19.

19. Bose A K, Mehrotra R M and Mushran S P, Indian J Chem., II,1973,896.

20. Mahadevappa D S, Rangappa K S, Gowda M M and Gowda B T, J Phys Chem., 1981, 85,3 651, Int.J.Chem.Kinet.1981, 14,1183, J Chem Soc Perkin Trans II,39, (1985) and Ref. (13) there in.

21. Ramanujam V M S and Trieff N M, J Chem Soc Perken Trans., II, 1975, 1590.

22. Radhakrishhnaamurti P S, Pati S C and Dev B R, Int J Chem Kinet., 1982, 14.

23.. Hassan Y I and Saeed N H M, J Educt Scince, 2008, 21,9, Saeed N H M, M.Sc.Thesis, University of Mosul,Mosul,Iraq, (2006).

24. Puttaswamy, Jadadeesh R V and Vaz N, Europ J Chem.,.2005, 3, 326.

25. Mahadevappa D S, Jadhav M B and Naidu H M K, Int J Chem Kinet., 1979, 11.261.

26. Jadhav M B, Naidu H M K and Mahadevappa D S, J Indian Chem Soc., 1980, 57, 693.

27. Mahadevappa D S and Gowda B T, Indian J Chem., 1979, 17, 484.

28. Ahmed M S, Gowda B T and Mahadevappa D S, Indain J Chem., 1980, 19, 650.

29. Metsger L and Bittner S, Tetrahedron, 2000, 51, 1905.

30. Vogel A I, "Text Book of practical organic chemistry" $4^{\text {th }}$ ed. Longman press, London, U.K.P, 1978, 651.

31. Morris J C, Salazar J A and Wineman M A, Am Chem Soc., 1948, 70, 2036.

32. Soloway S and Lipshits A, Anal Chem., 1952, 24, 898.

33. Gowda N M M and Mahadevappa D S, Talanta, 1970, 24, 470.

34. Cheronis N D and Entrikim J B, "Identification of organic compounds" See Ed., 1966, John Wikey and Sons ,New York ,U.S.A.

35. Vogel A I, "A Text-Book of Macro and Semimicro qualitative Inorganic Analysis" $4^{\text {th }}$ Ed., Longmans, London, U.K, 1965.

36. Gkerlof A and Amer J, Chem Soc., 1932, 54, 4125.

37. Bishop E and Jennings V J, Talanta, 1958, 1, 197.

38. Forst A A and Pearson R G "Kinetics and mechanism" $2^{\text {nd }}$ Ed., Wiley, New York U.S.A, 1961.

39. Laidler K J, "Reaction Kinetics"Progamon, 1962, New York, U.S.A, 1962.

40. Amis E S, Anal Chem., 1955, 27, 1672. 


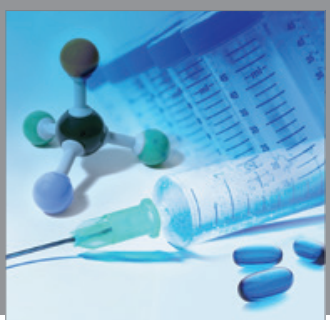

International Journal of

Medicinal Chemistry

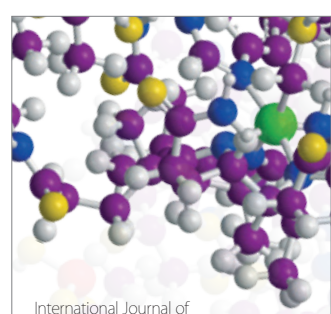

Carbohydrate Chemistry

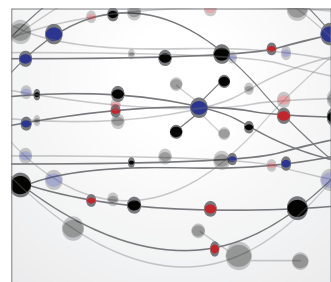

The Scientific World Journal
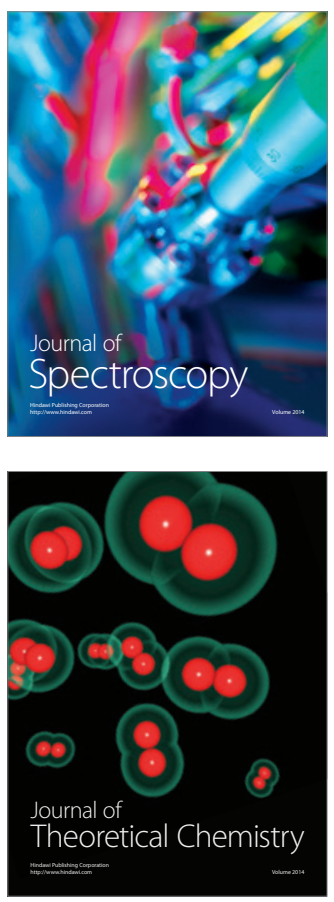
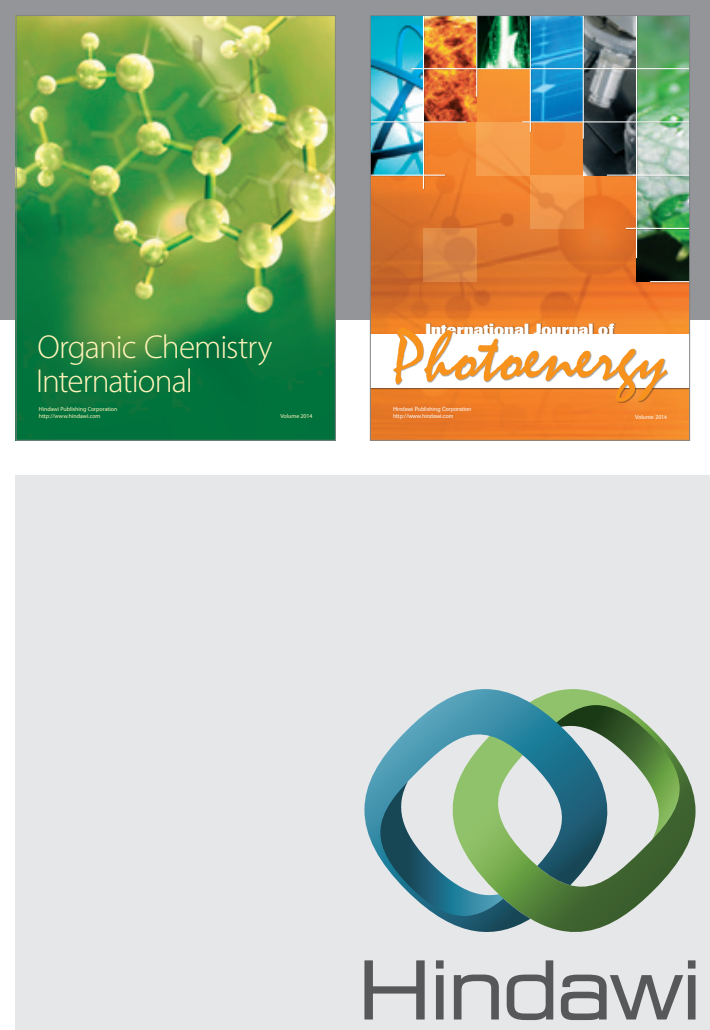

Submit your manuscripts at

http://www.hindawi.com
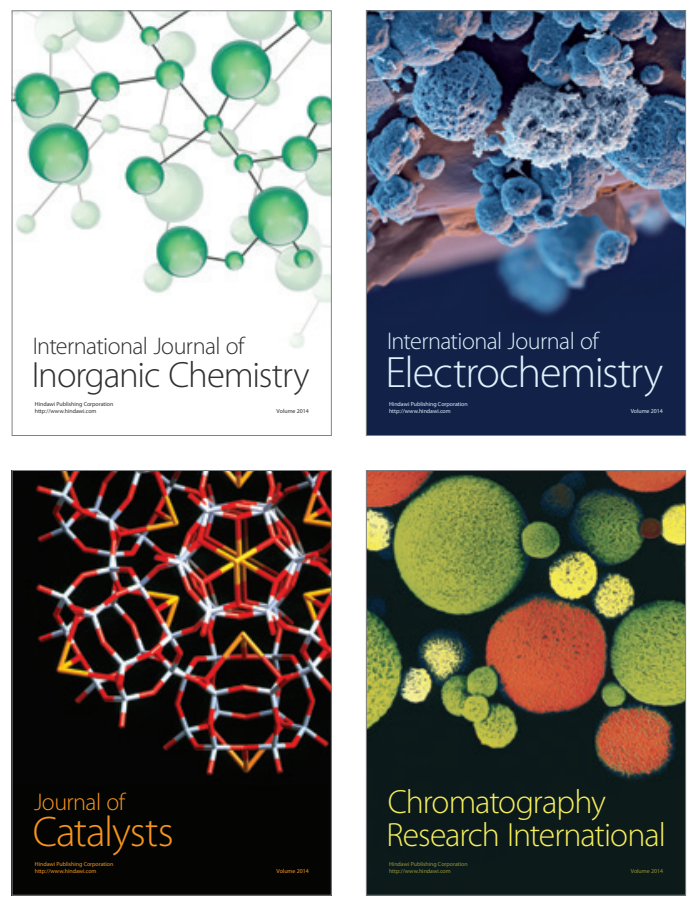
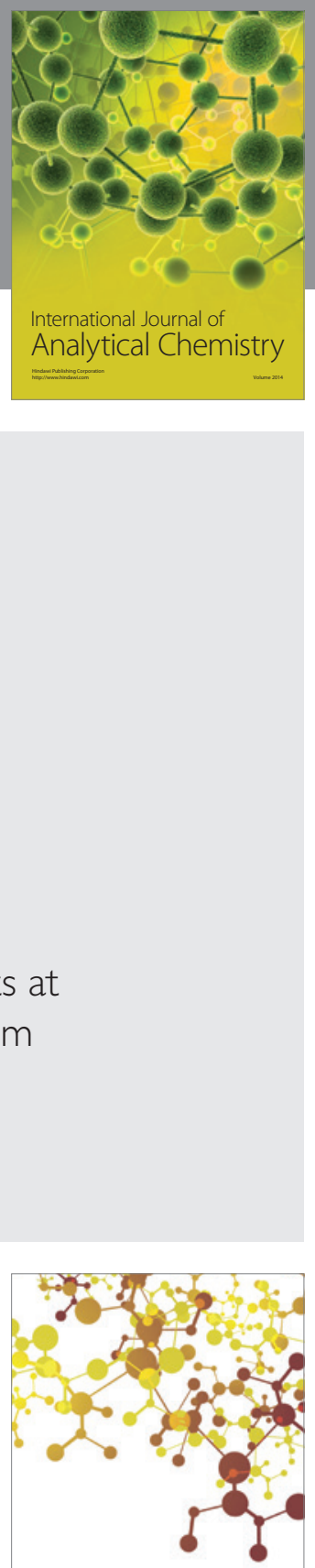

Journal of

Applied Chemistry
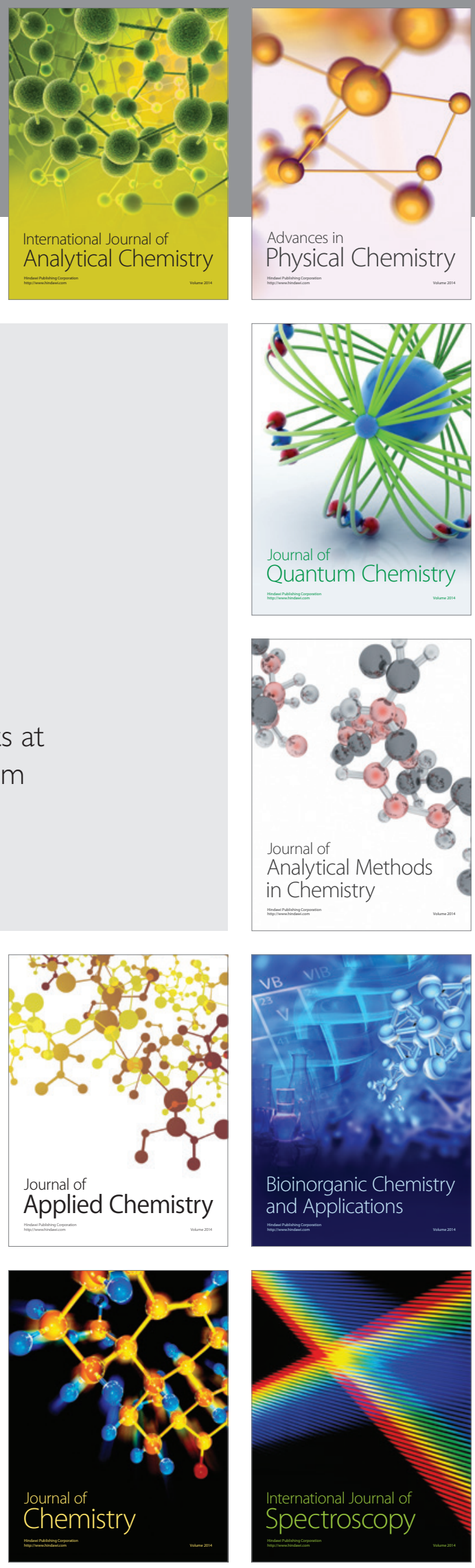